\title{
Diálogo sobre plantas medicinais: significados de escolares
}

\section{Diálogo sobre plantas medicinales: significado de los escolares Dialogue about medicinal plants: meanings of students}

\author{
Silvana Ceolin ${ }^{1}$, Marjoriê da Costa Mendieta ${ }^{2}$, Teila Ceolin ${ }^{3}$, Ana Carolina Padua Lopes ${ }^{4}$, Rita Maria Heck ${ }^{5}$ \\ ${ }^{1}$ Mestre em Enfermagem. Doutoranda do Programa de Pós-Graduação em Enfermagem (PPG-Enf) \\ da Universidade Federal de Pelotas (UFPel). \\ ${ }^{2}$ Mestre em Enfermagem. Doutoranda do PPG-Enf da UFPel. E-mail: marjoriemendieta@gmail.com \\ ${ }^{3}$ Doutora em Enfermagem. Professora da Faculdade de Enfermagem (FEn/UFPel).E-mail: teila.ceolin@gmail.com \\ ${ }^{4}$ Enfermeira pela UFPel.E-mail: kaupadualopes@yahoo.com.br \\ ${ }^{5}$ Doutora em Enfermagem. Professora associada do PPG-Enf da UFPel.E-mail: rmpillon@yahoo.com.br \\ Cómo citar este artículo en edición digital: Ceolin, S.,Mendieta, M.C., Ceolin, T., Lopes, A.C.P. y Ma Heck, R. (2016). Diálogo \\ sobre plantas medicinas: significados de escolares Cultura de los Cuidados (Edición digital),20(45). Disponible en: < http:// \\ dx.doi.org/10.14198/cuid.2016.45.11.> \\ Correspondencia: (remitirse al correo electrónico). \\ Correo electrónico: silvanaceolin@gmail.c \\ Recibido: 8/01/2016; Aceptado: 11/05/2016
}

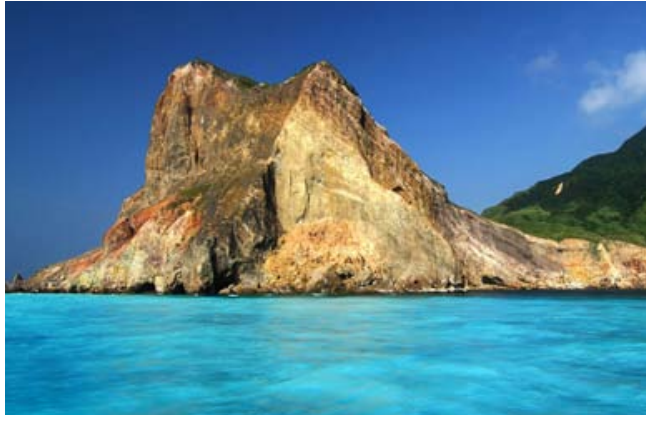

\section{ABSTRACT}

This study aims to know the meanings attributed by students to dialogue about medicinal plants in health care. It is a qualitative research with 65 students of two schools in the city of Pelotas/RS, from September 2011 to August 2012. The analyzed data was produced after 18 workshops from essays written by students and focus groups. The meetings allowed us to stimulate in the students values directed to the recognition of the family knowledge and the development of critical thinking about the safe use of medicinal plants, awakening them new visions of the world and providing a reflexion on the care practices. The use of
Geertz and Freire referential in the workshops allowed dialogue with the culture of the students and discuss situations of life, becoming in perspective for educational practice nurses.

Keywords: Health Education. School Health. Nursing. Culture. Medicinal plants.

\section{RESUMEN}

El artículo tiene como objectivo conocer los significados asignados por escolares sobre el diálogo cerca de las plantas medicinales en el cuidado de la salud. Metodología cualitativa con 65 escolares de dos escuelas del municipio de Pelotas/RS. La recolección de datos ocurrió de septiembre/2011 a agosto/2012. El material analizado fue produccido al final de 18 oficinas a partir de textos escritos y grupos focales. Se observó que los encuentros permitieron estimular en los estudiantes valores dirigidos al reconocimiento del saber familiar y el desarrollo del pensamiento crítico sobre el uso seguro de las plantas medicinales, levantando nuevas visiones del mundo y proporciando una reflexión sobre las prácticas de cuidado. El empleo del marco teórico de Geertz y Freire 
en las oficinas permitió el diálogo con la cultura de los escolares y discutir situaciones de vida, transcurriendo en una perspectiva para la educación de las enfermeras.

Palabras clave: Educación en Salud. Salud Escolar. Enfermería. Cultura. Plantas medicinales.

\section{RESUMO}

O estudo teve como objetivo conhecer os significados atribuídos pelos escolares ao diálogo sobre plantas medicinais no cuidado à saúde. Pesquisa qualitativa realizada com 65 escolares de duas escolas do município de Pelotas/RS, no período de setembro de 2011 a agosto de 2012. O material analisado foi produzido ao final de 18 oficinas a partir de redações escritas por escolares e de grupos focais. Os encontros possibilitaram estimular nos educandos valores direcionados ao reconhecimento do saber familiar e o desenvolvimento do pensamento crítico sobre o uso seguro de plantas medicinais, despertando novas visões de mundo e proporcionando uma reflexão sobre as práticas de cuidado. $\mathrm{O}$ emprego do referencial de Geertz e Freire nas oficinas permitiu dialogar com a cultua dos escolares e problematizar situações de vida, constituindo-se em perspectiva para a prática educativa do enfermeiro.

Palavras-Chave: Educação em saúde, Saúde escolar, Enfermagem, Cultura, Plantas medicinais.

\section{INTRODUÇÃO}

Um dos grandes desafios da sociedade, desde os tempos remotos até os dias atuais, é a manutenção do bem-estar. No entanto, a assistência à saúde, norteada pelo paradigma positivista, trabalha com uma visão fragmen- tada do ser humano e estabelece uma relação hierárquica, gerando impotência ao usuário. Esta perspectiva implica em menor autonomia do sujeito na condução da sua vida, visto que suas concepções de mundo para cuidar de sua saúde muitas vezes não são consideradas pelos profissionais de saúde no planejamento do seu cuidado.

No contexto do paradigma sóciocrítico, que introduz a prática reflexiva e o pensamento crítico no processo de construção do conhecimento, a saúde é entendida como um fenômeno complexo com raízes histórico-culturais que envolvem símbolos sociais (Siles, 1997). Em consequência, a educação em saúde não pode reduzir-se à visão biológica do processo, precisa ser exercitada de por meio de técnicas dialogadas com a cultura. O diálogo, em Freire, exige um pensar crítico e parte de uma situação concreta, a partir da qual há o repensar da prática e a edificação de processos de transformação (Freire, 2016).

Considerando a escola como um espaço de aprendizado e crescimento importante para o desenvolvimento social do cidadão (Alvarenga et al, 2012), esta é um local ideal para o diálogo de saberes sobre saúde, que, se trabalhados de acordo com referenciais problematizadores, 3 conduzem à mudanças sociais. O enfermeiro, como educador em saúde, pode se inserir neste ambiente para dialogar e estimular o pensamento crítico dos educandos.

Contemporaneamente, a saúde passou a ser considerada como um tema transversal a ser trabalhado na escola, considerando a necessidade de ações integradas entre educação e saúde. A intenção é trabalhar as necessidades próprias da cultura local que interferem na vida cotidiana dos educandos (Brasil, 2009).

A cultura consiste em estruturas de significados socialmente estabelecidas que conferem 
sentido às ações humanas. Tais significados são transmitidos historicamente e incorporados em símbolos, um sistema de concepções herdadas e expressas em formas simbólicas por meio das quais os homens comunicam, perpetuam e desenvolvem seu conhecimento e suas atividades em relação à vida (Geertz, 2011).

Para Geertz (2011), os significados são “armazenados" através de símbolos, que parecem resumir, de alguma maneira, o que se conhece sobre a forma como é o mundo e a maneira como quem está nele deve comportar-se. Para este autor, os acontecimentos não estão apenas "lá" e acontecem, mas têm um significado e ocorrem por causa desse. Assim, a interpretação de tais significados é essencial para conhecer a diversidade cultural e desenvolver práticas educativas em saúde.

Neste sentido, acredita-se que o compartilhamento do conhecimento popular sobre plantas medicinais no espaço escolar amplia possibilidades para o diálogo entre os saberes da comunidade e alguns conteúdos trabalhados em sala de aula, além de contribuir para preservar o saber familiar e associar outras experiências na vida da pessoa (Ceolin, 2012).

Assim, o enfermeiro como educador em saúde possui papel fundamental na construção do pensamento crítico dos escolares, para que os mesmos possam refletir sobre seu contexto de vida e tomar decisões conscientes relativas à sua própria saúde e da comunidade. A partir destas reflexões, foi formulada a seguinte questão de pesquisa: Quais são os significados atribuídos pelos escolares ao diálogo sobre plantas medicinais no cuidado à saúde? Portanto, o objetivo deste estudo é conhecer os significados atribuídos pelos escolares ao diálogo sobre plantas medicinais no cuidado à saúde.

\section{MATERIAL E MÉTODO}

Tratou-se de um estudo qualitativo exploratório e descritivo, vinculado ao projeto de pesquisa e extensão intitulado "Uso de plantas medicinais e as práticas populares de saúde entre escolares da região Sul do Rio Grande do Sul", desenvolvido pela Faculdade de Enfermagem da Universidade Federal de Pelotas em parceria com a Embrapa Clima Temperado. Este projeto é vinculado ao Programa Novos Talentos da Coordenação de Aperfeiçoamento de Pessoal de Nível Superior (CAPES), edital $n^{\circ} 055 / 2012$.

A pesquisa foi realizada com educandos de duas escolas públicas da região periférica do município de Pelotas/RS, região caracterizada por alta vulnerabilidade econômica e social. As atividades foram desenvolvidas com 26 escolares matriculados no 50 ano e 29 no 60 ano de uma escola municipal e com 28 escolares do 50 ano de uma escola estadual, perfazendo, neste primeiro momento, 83 educandos.

$\mathrm{Na}$ primeira etapa, foram implementadas 18 oficinas (seis por turma) com os 83 escolares, sendo seis nas escolas e doze na universidade (hortas de plantas medicinais e laboratórios), durante o período de setembro a dezembro de 2011, nas quais foram abordadas questões teóricas e práticas sobre saúde e plantas medicinais, em uma visão que engloba a relação humana com o ambiente.

Resumidamente, os temas das oficinas podem ser agrupados da seguinte forma: plantas medicinais mais utilizadas pelos escolares e suas famílias; perspectiva cultural do uso de plantas medicinais; aspectos básicos das plantas medicinais e sua ação no corpo humano; cuidados com as plantas medicinas (plantio, colheita, identificação, higienização, secagem, armazenamento; formas de preparo e manipulação para o consumo, indicações e efeitos 
colaterais); interface entre plantas medicinais, saúde e sustentabilidade.

Dentre os recursos didáticos utilizados, destaca-se: discussões em roda, cartazes, pinturas, jogo da memória, vídeos, atividades no laboratório de plantas e no horto didático de plantas medicinais. Em todas as oficinas ocorreram momentos de prática, como plantio de mudas e manipulação de plantas para o consumo. Foi realizado um trabalho integrado com os professores de cada turma, que também analisaram as produções dos educandos, enquadrando-as como recursos avaliativos para a disciplina curricular.

As oficinas foram coordenadas por três mestrandas e seis bolsistas de iniciação científica do grupo de pesquisa, que foram capacitados previamente e distribuídos para trabalhar com as três turmas de escolares. Algumas atividades contaram também com convidados (um agrônomo e uma fisioterapeuta) que contribuíram para a interdisciplinaridade das discussões.

As oficinas tiveram como embasamento teórico para sua execução o referencial teórico de Clifford Geertz e Paulo Freire. Geertz (2011) diz que a cultura não é estática, mas construída pelos sujeitos ao interagirem no cotidiano. Para Freire (2016), os processos educativos devem ser mediados pelo diálogo ente as culturas, pela problematização das experiências e ação dos sujeitos. No campo da saúde, a articulação desses autores fundamenta um processo de educação em saúde culturalmente sensível, no qual os agentes compartilham conhecimentos e fortalecem seus saberes e práticas de cuidado em saúde. Ao final destes seis encontros, foi solicitado que os escolares escrevessem uma redação a partir da pergunta norteadora: "O que as oficinas representaram na minha vida?”.
Dos 83 escolares, 65 escreveram a redação e compuseram a totalidade dos sujeitos da pesquisa. As redações ficaram distribuídas da seguinte maneira: 25 do quinto ano, 25 do sexto ano (ambos da escola municipal) e 15 do quinto ano (escola estadual), totalizando 65 redações. Do total escolares integrantes do estudo, 51\% são do sexo feminino. A idade dos sujeitos variou entre 9 e 15 anos.

A segunda etapa da pesquisa ocorreu nos meses de julho e agosto de 2012 com estes 65 educandos. Foram realizados três grupos focais, sendo um com cada turma. Estes foram compostos por 10 escolares de cada turma elencados por sorteio aleatório. Para a coleta de dados no grupo focal utilizou-se gravador.

O desenvolvimento desta técnica contou com a presença de um mediador, um observador e um responsável pela gravação, todos anteriormente capacitados para a realização da atividade. Os grupos focais foram realizados em uma sala da Faculdade de Enfermagem da Universidade Federal de Pelotas em dia e horário combinados com os escolares e professores, tendo duração de aproximadamente 50 minutos.

Os dados que emergiram das redações e dos grupos focais foram analisados por meio da proposta operativa de Minayo (2015), que abrange três etapas: ordenação dos dados, classificação dos dados e análise final.

Em sequência, os dados foram classificados em três temas: 1) diálogo sobre plantas medicinais; 2) cuidado com a saúde; 3) cuidado com o ambiente. Neste artigo será abordado o primeiro tema. Na discussão dos resultados apresentados, "texto escrito" refere-se às redações e "discurso oral" aos grupos focais.

$\mathrm{O}$ estudo foi conduzido seguindo os preceitos éticos contidos Resolução do Conselho Nacional de Saúde (466/2012)(Brasil, 2012). 
Os escolares e seus responsáveis assinaram o Consentimento Livre e Esclarecido. Para manter o anonimato dos sujeitos, os mesmos foram identificados por nomes de plantas medicinais. O projeto foi aprovado pelo Comitê de Ética e Pesquisa da Faculdade de Medicina da Universidade Federal de Pelotas, protocolo 020/2011.

\section{RESULTADOS E DISCUSSÃO}

Pesquisas reconhecem a importância dos elementos culturais no cuidado à saúde e a necessidade de conhecê-los. Dentre estes elementos, destacam-se as plantas medicinais, sua origem, uso e transmissão do saber (Meléndez e González, 2016).

O conhecimento dos estudantes sobre o uso de plantas medicinais foi adquirido com os familiares. Algumas falas remetem à proximidade que este tema proporciona com a família.

Minha mãe faz chá pra mim quando estou mal do estômago (Poejo, discurso oral).

Quando eu estava doente, minha mãe fazia chá de hortelã pra mim (Mil-folhas, discurso oral)

A vó planta babosa, serve para ajudar no tratamento do câncer (Acerola, discurso escrito).

A maioria da população é migrante da área rural, e ainda mantém a tradição do uso de plantas medicinais no cuidado à saúde. Em trabalho anterior, realizado por Mesquita (2011) desenvolvido com as famílias dos mesmos estudantes, foram realizadas entrevistas no domicílio, as quais citaram o uso de diversas plantas medicinais (pelo nome popular): alfavaca, alfazema, babosa, boldo, camomila, capim cidreira, cavalinha, cidrozinhho, espi-

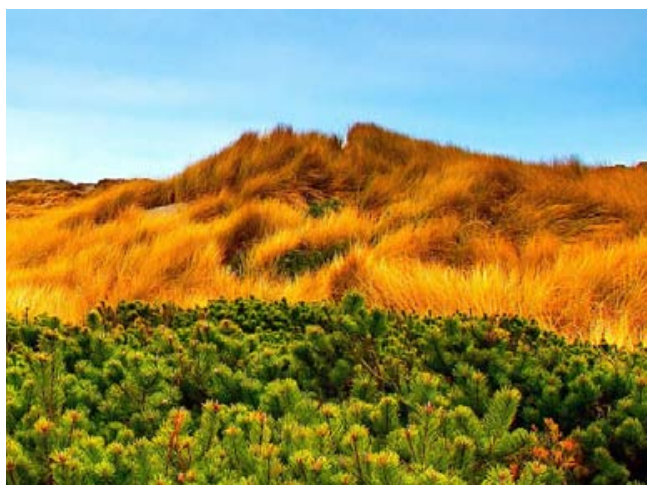

nheira santa, funcho, hortelã, malva, mil em ramas, poejo, quebra-pedra, sálvia brasileira, sálvia da gripe, tansagem. Nesta ótica, entende-se que as práticas de saúde são construídas e perpetuadas a partir dos costumes e tradições socioculturais, ligados à rede familiar e à comunidade.

Os escolares declaram que a difusão de informações e experimentação do uso de plantas medicinais no cuidado ocorre no meio familiar. Tais constatações vão ao encontro de estudos que evidenciam a família como principal fonte de experimentação e transmissão do saber em relação às plantas medicinais (Ceolin, 2011; Marinho, 2011). Tais evidências remetem a compreensão de que o uso de plantas no ambiente familiar expressa um sentido de vinculação e trocas entre membros, decorrente de um saber construído no mundo vivido, ou seja, ancorado nas concepções e práticas culturais.

Observa-se nos discursos a menção da figura feminina na execução do cuidado em saúde familiar. Esta percepção é destacada também por estudos (Ceolin, 2011; Badke, 2012) que demonstram a predominância do gênero feminino nas práticas de cuidado com plantas medicinais, revelando a importância das mulheres na transmissão deste saber entre as gerações. 
Os discursos dos estudantes traduzem suas concepções sobre planta medicinal e destacam as contribuições das oficinas na construção do seu conhecimento, conforme relatos que seguem:

Com as oficinas entendi que podemos usar uma planta para cuidar da nossa saúde (Alecrim, discurso oral).

Foi muito legal essa aprendizagem das oficinas, porque nos ajudou a ter uma saúde melhor com as plantas (Poejo, discurso escrito).

As plantas medicinais fazem bem para a nossa saúde, para a nossa vida e para a natureza (Sene, discurso escrito).

Elas (plantas medicinais) têm vários benefícios para curar a gente (Manjerona, discurso escrito).

Uma planta que pode ser usada na medicina (...) pode prevenir doenças (Menta, discurso oral).

Os enunciados mostram que as crianças possuem em sua vivência percepções sobre o uso de plantas medicinais no processo saúde-doença. Consideram as plantas como um recurso para manter a saúde, prevenir e tratar doenças. Diferente deste resultado, pesquisas sobre uso de plantas medicinais por diferentes populações revelam que a indicação e uso das mesas estão relacionados principalmente ao tratamento de enfermidades (Freiras et al, 2012) 14. Esta concepção visualiza a planta como um medicamento, distanciando-se dos conceitos de prevenção de doenças e promoção da saúde.

No contexto de uma sociedade de cultura medicalizante e capitalista, que transforma elementos culturais em produto para o consumo, a real filosofia do uso de plantas, ou seja, manter o equilíbrio dinâmico entre os com- ponentes do ser humano e o ambiente, acaba presa na rigidez deste sistema.

Além da crença das plantas como um recurso preventivo e terapêutico, as expressões dos educandos revelam um sentido amplo do benefício das plantas, pois as remetem como um símbolo de vida no seu contexto cultural. Considerando que as concepções de cuidado e saúde são culturalmente construídas (Geertz, 2011), as experiências adquiridas na família, comunidade e escola integram o pensar e agir cotidiano dos educandos.

Com o propósito de que a escola trabalhe de forma integrada com as necessidades da localidade, considerando-as em sua complexidade, a Lei de Diretrizes e Bases da Educação Nacional (LDBEN 9394/96) expôs a necessidade de trabalhar no ambiente escolar temas vinculados ao cotidiano dos educando (como saúde, ambiente, ética e cultura). A intenção é que tais temas sejam contemplados transversalmente, ou seja, perpassando entre os conteúdos tradicionais, sem restringir a uma única área de conhecimento (Brasil, 1996).

A integração entre saúde e educação, de forma contextualizada com a cultura local, torna-se mais significativa a quem vivencia. Foi com esta intencionalidade que propomos aos escolares a discussão sobre o processo saúde-doença-cuidado, aproximando a diversidade de saberes, com o desafio de contribuir para a reflexão crítica sobre sua saúde e o ambiente que os cerca.

Neste panorama, a educação em saúde deixa de ser ato de transferência de conhecimentos e valores e pode ser construída na relação com o mundo e com o outro, na qual os sujeitos são convidados a deixar o silêncio e a passividade para compartilhar suas experiências de vida (Freire, 2015). 
A partir do diálogo sobre ambiente, plantas e saúde, os escolares expuseram seu entendimento sobre a relação entre estes temas:

Cuidar bem direitinho das plantas, das árvores, do canteiro, é também cuidar da nossa saúde, do nosso organismo (Marcela, discurso escrito).

Eu dizia para minha mãe que não precisava cuidar das plantas porque elas vêm da natureza. Mas depois eu entendi a minha mãe. É muito importante porque as plantas precisam estar saudáveis para nós. Agora todas as plantas que eu acho na rua, no campo, eu pego, levo para minha casa e lá eu cuido delas (Bardana, Discurso escrito).

Entende-se que as concepções dos escolares foram sendo ressignificadas a partir do diálogo entre o conhecimento popular e o científico. No contexto destes discursos, a saúde é compreendida a partir de um enfoque amplo, de forma interligada com a natureza, sendo a planta um símbolo de cuidado.

As explanações dos educandos remetem à concepção de integralidade, fruto da reorientação das formas de agir em saúde (Fraciolli et al, 2011). Tal abordagem percebe o ser como sujeito histórico, social e político, dentro de um contexto familiar e comunitário que se articula com o meio social e ambiental. Esta perspectiva envolve ações de educação, como produção de saber coletivo, levando o ser humano à emancipação e à autonomia para cuidar de si, de sua família e do meio em que vive (Rosito e Lotério, 2012).

Inserido no ambiente escolar, o enfermeiro pode desenvolver práticas educativas em saúde com o intuito de somar conhecimentos e refletir em conjunto com o outro, na busca de alternativas de cuidado que produzam signifi- cado a quem vivencia. Assim, entende-se que as percepções relacionadas ao cuidado com plantas medicinais estão associadas às crenças e práticas estabelecidas ao longo de suas vivências e evidenciam o contexto cultural dos mesmos.

A partir da contextualização com sua realidade, os educandos foram motivados a refletirem sobre a importância das plantas medicinais para a saúde e sobre a valorizar o saber familiar. Neste cenário, foi proposto o diálogo com o conhecimento científico por meio da realização de oficinas no espaço da universidade e da escola. A intenção era de que tivessem aporte teórico e prático. Assim, foi oportunizado aos educandos falar, olhar, tocar, cheirar e plantar uma muda, conhecer a identificação botânica e as indicações das plantas. Esta aprendizagem vivenciada sobre os cuidados para a utilização das plantas medicinais foi enunciada pelos escolares:

As oficinas de plantas medicinais significaram muito pra mim. Plantei muitas e aprendi a cuidar delas. E adorei a horta aqui da escola (Alho, discurso escrito).

Eu estou aprendendo muito e nessas oficinas tem muita coisa legal, porque eu estou aprendendo como fazer chá, plantar, colher as ervas, guardar e usá-las (Calêndula, discurso escrito).

Também a possibilidade de efeitos colaterais passou a fazer parte da manifestação dos escolares:

(...) nem todas as plantas fazem bem ao nosso corpo. Também tem várias plantas que não foram identificadas porque não têm flores ou frutos. Aprendi que se eu ainda não identifiquei a planta não é seguro tomar o seu chá. Eu sei que 
uma parte das oficinas eu vou esquecer, mas o resto nunca irei esquecer (Guaco, discurso escrito).

É importante fazer um chá com a dosagem certa e ficar de olho para ver se não vai prejudicar. Se passar mal, vá até a pessoa que lhe deu a planta e pergunte de onde ela colheu (Maracujá, discurso oral).

As oficinas de plantas medicinais me ensinaram a ter mais cuidado com as plantas e também saber as que me prejudicam se forem utilizadas de qualquer maneira (Hibisco, discurso escrito).

O intuito destas discussões foi de dialogar com os escolares sobre as informações trazidas do seu cotidiano para que eles qualificassem o cuidado com as plantas. Quanto aos cuidados na colheita, identificação, preparo, armazenamento e consumo das plantas, as crianças demostraram consciência da importância destas etapas serem realizadas com precaução. Conseguiram refletir sobre a possibilidade de surgirem efeitos colaterais e/ou tóxicos no uso desta terapêutica.

Divergindo desse resultado, uma pesquisa aponta que as representações sociais sobre plantas medicinais parecem estar ancoradas na concepção de segurança, pois geralmente são vistas apenas em seus aspectos positivos, como uma opção considerada natural e com pouco ou nenhum efeito colateral (Lima et al, 2012).

A compreensão do processo educativo exercitado leva a afirmar que a metodologia utilizada, a qual permitiu diálogo, aproximação cultural e atividades práticas, foi apropriada à sensibilização dos escolares. Destaca-se que o enfermeiro pode atuar na orientação sobre o uso de plantas medicinais, objetivando a formação da consciência crítica sobre o uso precavido destas.

Em alguns momentos, os educandos relataram que os momentos de prática (preparações a partir de plantas medicinais, produção de uma muda e construção de um canteiro na escola) foram os mais relevantes nas oficinas. Este resultado tem suporte nas ideias de Paulo Freire, para o qual as práticas educativas só se tornam significativas, e, portanto, resultam em conscientização, se tiverem como ponto de partida a experiência concreta e a ação do sujeito (Freire, 2016).

Nos depoimentos dos escolares, também se perceberam os significados que foram sendo construídos a cada encontro, mediante diálogo com as influências provenientes da cultura em que estão inseridos.

Eu aprendi várias coisas para minha vida. Eu nunca dava importância para as plantas, mas depois que eu coloquei os meus dois pés aqui, ficou tudo diferente, eu me sentia diferente. Foi assim que comecei a dar valor para as plantas, elas servem para muitas coisas que eu não sabia (Bardana, discurso escrito).

Eu aprendi a cuidar das plantas e a gostar. Isso representou melhorias no meu conhecimento. Eu conheci ervas diferentes. Eu conheci uma planta que eu nunca tinha visto, o nome da planta é manjericão. Esse projeto mudou um pouco de minha vida porque eu aprendi várias coisas, eu aprendi cuidar das plantas, eu aprendi gostar das plantas (Babosa, discurso oral).

O exercício de integrar família, escola e universidade trouxe mudança na percepção dos escolares. Inserir o conhecimento do educando no espaço da universidade contribuiu 
para ressignificar valores referentes às plantas medicinais, em uma perspectiva que engloba o cuidado em saúde de maneira integral, ou seja, conectada ao ambiente.

As estratégias pedagógicas utilizadas, baseadas na vivência experimental e troca de saberes, colaboraram para proporcionar o vínculo com os escolares e despertar o interesse na valorização das práticas populares de cuidado, revelando os significados que os diálogos e a aprendizagem sobre plantas medicinais representaram para a sua vida.

\section{CONSIDERAÇÕES FINAIS}

O desenvolvimento de práticas educativas em saúde culturalmente sensíveis com o contexto dos escolares permitiu conhecer os significados que os mesmos atribuíram ao diálogo sobre plantas medicinais.

A socialização do sistema de crenças, valores e práticas de cuidado dos educandos com o universo acadêmico contribui para o processo de sensibilização destes em relação aos cuidados com o uso de plantas medicinais, de forma a despertar novas visões de mundo, ressignificando as práticas de cuidado.

A intencionalidade de aproximar a abordagem utilizada nas oficinas e nos grupos focais do referencial teórico de Paulo Freire e Clifford Geertz permitiu visualizar os escolares inseridos em sua cultura e aproximá-los do mundo universitário, estimulando-os a se apropriarem deste outro saber e a dialogarem com os conceitos produzidos em sua cultura. Este encontro possibilitou estimular nos educandos valores direcionados ao reconhecimento do saber familiar e o desenvolvimento do pensamento crítico sobre o uso seguro de plantas medicinais no cuidado à saúde.

Nesta perspectiva, é importante enfatizar a importância da aproximação do ensino, pesquisa e extensão para a comunidade criar condições de analisar criticamente seu contexto e usufruir do conhecimento universitário produzido. A área da saúde reúne condições privilegiadas para este encontro, desde que seus profissionais estejam atentos e disponíveis para compartilhar saberes e práticas.

Assim, os profissionais de saúde, e especialmente o enfermeiro, têm o compromisso de procurar interpretar os símbolos e significados socialmente construídos nas diferentes culturas para propor uma prática educativa em saúde que produza significados ao existir.

Seguindo a ideia da reflexão e da ação propostas neste artigo, recomenda-se a realização de outras pesquisas junto à comunidade escolar, que possam explorar a utilização das diversidades para ensinar, tais como investigar a troca de saberes sobre plantas medicinais entre as famílias de escolares; a proposta de educação em saúde com plantas medicinais no currículo escolar e a percepção dos professores sobre educação em saúde. Trata-se de reforçar a necessidade e a importância de metodologias problematizadoras para estimular a autonomia dos educandos no cuidado individual e coletivo.

\section{REFERÊNCIAS}

- Alvarenga, W.A., Silva, M.E.D.C., Silva, S.S., Barbosa, L.D.C.S. (2012). Ações de educação em saúde realizadas por enfermeiros na escola: percepção de pais. Revista Mineira de Enfermagem, 16(4), 522-27.

- Badke, M.R, Budó, M.L.S., Alvim, N.A.T., Zanetti, G.D., Heisler, E.V. (2012). Saberes e práticas populares de cuidado em saúde com o uso de plantas medicinais. Texto \& contexto enfermagem, 21(2), 363-70.

- Brasil. Departamento de Atenção Básica. (2009) Saúde na escola. Brasília: Ministério da Saúde.

- Brasil. Conselho Nacional de Saúde. Comissão Nacional de Ética em Pesquisa. (2012). Resolução no 466 de 12 de dezembro de 2012: diretrizes e normas regulamentadoras de pesquisa envolvendo seres humanos. Brasília: Ministério da Saúde. 
- Brasil. Diário Oficial da República Federativa do Brasil. (1996). Lei no 9394 de 20 de dezembro de 1996. Estabelece as diretrizes e bases da educação nacional. Brasília: Ministério da Saúde.

- Ceolin, S. (2012). O processo de educação em saúde a partir do diálogo sobre plantas medicinais: significados para escolares. (Dissertação de mestrado não publicada). Programa de Pós-graduação em Enfermagem, Universidade Federal de Pelotas: Pelotas/RS/Brasil. Recuperada de: http://wp.ufpel.edu.br/pgenfermagem/files/2015/10/ 3295c76acbf4caaed33c36b1b5fc2cb1.pdf

- Ceolin, T, Heck, R.M., Barbieri, R.L., Schwartz, E., Muniz, R.M., Pillon, C.N. (2011). Plantas medicinais: transmissão do conhecimento nas famílias de agricultores de base ecológica da região Sul do Rio Grande do Sul. Revista da Escola de Enfermagem da USP, 45(1), 47-54.

- Fracolli, L., Zoboli, E.L.P., Granja. G.F., Ermel. R.C. (2011). Conceito e prática da integralidade na Atenção Básica: a percepção das enfermeiras. Revista da Escola de Enfermagem da USP, 45(5), 1135-1141.

- Freire, P. (2016). Pedagogia da autonomia: saberes necessários à prática educativa. São Paulo: Paz e Terra; 2016.

- Freire P. (2015). Pedagogia do oprimido. Rio de Janeiro: Paz e Terra.

- Freitas, A.V.L., Coelho, M.F.B., Maia, S.S.S., Azevedo, R.A.B. (2012). Plantas medicinais: um estudo etnobotânico nos quintais do Sítio Cruz, São Miguel, Rio Grande do Norte, Brasil. Revista Brasileira de Biociências, 10(1), 48-59.
- Geertz, C. (2011). A interpretação das Culturas. Rio de Janeiro: LTC.

- Lima, S.C.S., Arruda, G.O., Renovato, R.D., Alvarenga, M.R.M. (2012). Representações e usos de plantas medicinais por homens idosos. Revista Latino-Americana de Enfermagem, 20(4),778-86.

- Marinho, M.G.V., Silva, C.C., Andrade, L.H.C. (2011). Levantamento etnobotânico de plantas medicinais em área de caatinga no município de São José de Espinharas, Paraíba, Brasil. Revista Brasileira de Plantas Medicinais, 13(2), 170-82.

- Meléndez, F.C., González, A.Y.V. (2016). Ambiente y patrimonio cultural. Cedes: México.

- Mesquita, M.K. (2011). Uso de plantas medicinais entre famílias de escolares (Monografia de graduação). Faculdade de Enfermagem, Universidade Federal de Pelotas: Pelotas/RS/Brasil.

- Minayo, M.C.S. (2015). O desafio do conhecimento: pesquisa qualitativa em saúde. São Paulo: Hucitec.

- Rosito, M.M.B., Lotério, M.G. (2012). Formação do profissional em saúde: uma recusa ao esvaziamento da essência do cuidado humano. Educação \& Realidade, 37(1),125-142.

- Siles, J. (1997). Epistemología y enfermería: por una fundamentación científica y profesional de la disciplina. Enfermería Clínica, 4(7), 188-194.

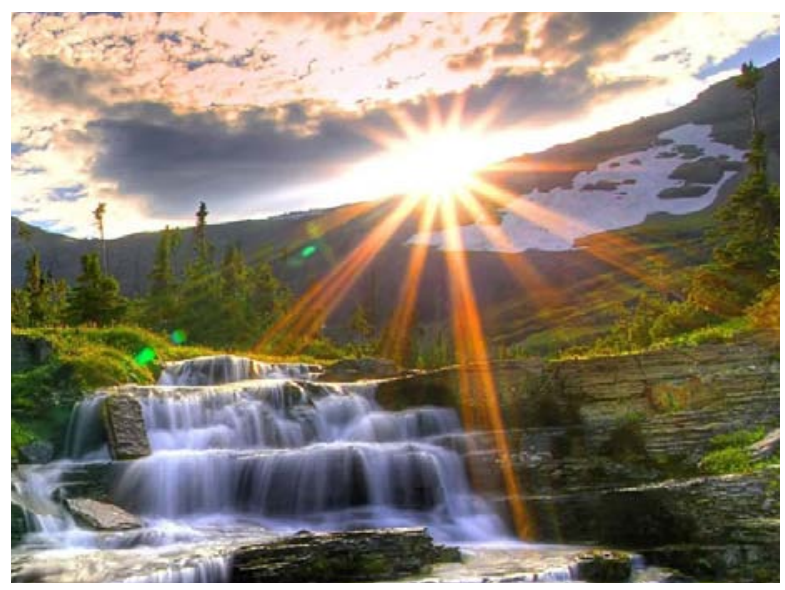

